\title{
The pH Rule for Fabricating Composite CoCu Nanowire Arrays
}

\author{
Xiaoxu Liu, ${ }^{1}$ Jianling Zhao, ${ }^{1}$ Yangxian $\mathrm{Li},{ }^{1}$ Shifeng Xu, ${ }^{2}$ Zhiyong Zhu, ${ }^{2}$ Jinglan Chen, ${ }^{2}$ and Guangheng Wu*2 \\ ${ }^{1}$ School of Material Sciences and Engineering, Hebei University of Technology, Tianjin 300130, P. R. China \\ ${ }^{2}$ State Key Laboratory for Magnetism, Institute of Physics Chinese Academy of Scineces, Beijing 100080, P. R. China
}

(Received October 23, 2006; CL-061245; E-mail: ghwu@aphy.iphy.ac.cn)

\begin{abstract}
A series of $\mathrm{Co}_{1-x} \mathrm{Cu}_{x}(x=0.05-0.70)$ composite nanowire arrays have been electrodeposited in alumina templates. An apparent $\mathrm{pH}$ value rule for nanowire phase and composition has been found. Based on it, composite nanowires can be obtained and the composition becomes more controllable. In the composite nanowires, the cubic and hexagonal structures coexisted. The specific magnetic properties, coercivity and squareness of the composite arrays are enhanced by three times, apparently preceding to those in single phase nanowires.
\end{abstract}

In the investigation of magnetic nanowire arrays, ${ }^{1,2}$ more and more ferromagnetic-nonmagnetic alloy systems, including $\mathrm{CoCu}$, have been reported for exhibiting special magnetic characters. ${ }^{3-6}$ For $\mathrm{CoCu}$ nanowires, most studies mainly focus on $\mathrm{Co} / \mathrm{Cu}$ multilayer, ${ }^{3,4}$ or the face-centered cubic (fcc) single phase, ${ }^{3,5}$ and very few literature has been found on the fabrication and characterization of composite $\mathrm{CoCu}$ nanowires. The magnetic properties of the composite Co-based nanowire should be much better than the single phase nanowires, because more boundaries and grain surfaces can improve the effective anisotropy and enhance the magnetic coercivity.

In this paper, a series of $\mathrm{CoCu}$ electrodepositing experiments have been carried out under the different $\mathrm{pH}$ values and potentials. We found that the structure and the composition dependences exhibit a strong $\mathrm{pH}$ value rule: 1) the nanowires with wider composition range can be prepared by using a moderate $\mathrm{pH}$ value of $3.3 ; 2$ ) using this $\mathrm{pH}$ value, the nanowires are of composition with hexagonal close packed (hcp) and fcc structures. Due to containing rich phase boundaries, the magnetic properties of the nanowire arrays apparently precede to those in single phase samples.

Nanoporous anodized alumina oxide (AAO) templates with diameter of $50 \mathrm{~nm}$ were prepared by a two-step anodization process. The $\mathrm{CoCu}$ nanowires were electrodeposited into the pores by DC electrolysis in an electrolyte consisting of $0.08 \mathrm{M}$ $\mathrm{CoSO}_{4}, 0.008 \mathrm{M} \mathrm{CuSO}_{4}\left(\mathrm{Co}^{2+}: \mathrm{Cu}^{2+}=10: 1\right)$, and $0.5 \mathrm{M} \mathrm{H}_{3} \mathrm{BO}_{3}$. The $\mathrm{pH} 3.1,3.3$, and 3.5 are adjusted by adding $\mathrm{NaOH}$ solution. The electrodeposition of $\mathrm{Co}_{1-x} \mathrm{Cu}_{x}$ nanowires was carried out at different depositing potentials $(-1.0$ to $-1.4 \mathrm{~V})$ at given $\mathrm{pH}$ values. The chemical compositions of the nanowires were determined by energy-dispersed X-ray spectrometry (EDXS), the microstructure and magnetic properties were detected by transmission electron microscopy (TEM), X-ray diffraction (XRD) and vibrating sample magnetometer (VSM).

A series of $\mathrm{Co}_{1-x} \mathrm{Cu}_{x}$ nanowire arrays have been obtained by electrodeposition in the AAO templates. The nanowires are all straight and parallel to each other with uniform diameter of $50 \mathrm{~nm}$ and total length of about $15-20 \mu \mathrm{m}$.

Table 1 shows the $\mathrm{Co}_{1-x} \mathrm{Cu}_{x}$ composition and structure dependence of $\mathrm{pH}$ values and depositing potentials. The $\mathrm{Cu}$ content
Table 1. The composition $(\mathrm{Co}: \mathrm{Cu})$ and structure of deposited $\mathrm{CoCu}$ nanowires at different $\mathrm{pH}$ values and depositing potentials

\begin{tabular}{cccc}
\hline \multirow{2}{*}{ Potential/V } & \multicolumn{3}{c}{$\mathrm{pH}$} \\
\cline { 2 - 4 } & 3.1 & 3.3 & 3.5 \\
\hline-1.0 & $71: 29$ (hcp) & $38: 62$ (fcc\&hcp) & $30: 70$ (fcc) \\
-1.1 & $77: 23$ (hcp) & $49: 51$ (fcc\&hcp) & $42: 58$ (fcc) \\
-1.2 & $84: 16$ (hcp) & $60: 40$ (fcc\&hcp) & $46: 54$ (fcc) \\
-1.3 & $90: 10$ (hcp) & $75: 25$ (fcc\&hcp) & $53: 47$ (fcc) \\
-1.4 & $95: 5$ (hcp) & $87: 13$ (fcc\&hcp) & $65: 35$ (fcc) \\
\hline
\end{tabular}

is in a large composition range of $x=0.05-0.70$ and monotonously increases with the increase of the depositing potential. The fact that $\mathrm{Cu}$ rich samples (for example, $\mathrm{Co}_{0.30} \mathrm{Cu}_{0.70}$ ) still can be deposited in these rich $\mathrm{Co}^{2+}$ solutions implies that the depositing rate of $\mathrm{Cu}$ is much higher than that of $\mathrm{Co}$. This result was also reported in previous works. ${ }^{3,5}$

Comparing to the potential, however, the $\mathrm{Cu}$ depositing rate is more sensitive to the $\mathrm{pH}$ values. At $\mathrm{pH} 3.1$, the copper concentration ranged in 5-29\% which is a Co-rich composition, and at $\mathrm{pH} 3.5$, it ranges in 35-70\% turning to $\mathrm{Cu}$-rich side. Therefore, a moderate $\mathrm{pH}$ value, $\mathrm{pH} 3.3$ provides a good condition for covering a wide range of $\mathrm{Cu}$ content of 13-62\%, as shown in Table 1, and thus the $\mathrm{Cu}$ concentration becomes more controllable.

The structures of all nanowire arrays have been examined by $\mathrm{XRD}$, as also listed in Table 1 . It can be seen that, for relatively low $\mathrm{pH}$ of 3.1, the samples formed as hcp structure. For high $\mathrm{pH}$ of 3.5 , the arrays were dominated by fcc $\mathrm{CoCu}$ alloy.

Based on the fact that the single hcp or fcc structures are supported by using $\mathrm{pH} 3.1$ and 3.5 , respectively, one may believe that the composite phase with fcc and hcp can be obtained by using a moderate condition of $\mathrm{pH}$ value. At $\mathrm{pH} 3.3$ is taken, a composite phase, hcp plus fcc structures have been obtained in overall $\mathrm{Co}: \mathrm{Cu}$ range from 87:13 to 38:62 as shown in Table 1. It should be noted that the composite nanowires have a wide composition range even covered those of single phase samples. Therefore, we may conclude that the results in Table 1 indicate an apparent $\mathrm{pH}$ value rule: contrasting to the usage for lower or higher $\mathrm{pH}$ values to producing $\mathrm{Co}-$ or $\mathrm{Cu}$-rich composition and single phase, the optimized $\mathrm{pH}$ value of 3.3 supports the nanowires depositing in a composite phase and additionally, in a wider composition range. This result can be attributed to that the $\mathrm{pH}$ value strongly affects the depositing rate of $\mathrm{Cu}^{2+}$, which further dominates the overall composition and the structure of the nanowires. This effect has also been observed in the works on pure Co nanowires. ${ }^{2}$

Figure 1 shows the detail XRD results of $\mathrm{Co}_{1-x} \mathrm{Cu}_{x}$ nanowire arrays prepared under $\mathrm{pH} 3.3$ condition. For all samples, hcp $\operatorname{Co}(100)$ peak can be clearly observed, which indicates the hcp Co always exists in nanowires. For Co-rich sample of $\mathrm{Co}_{87} \mathrm{Cu}_{13}$, only (100) peak of hcp Co can be observed. This 


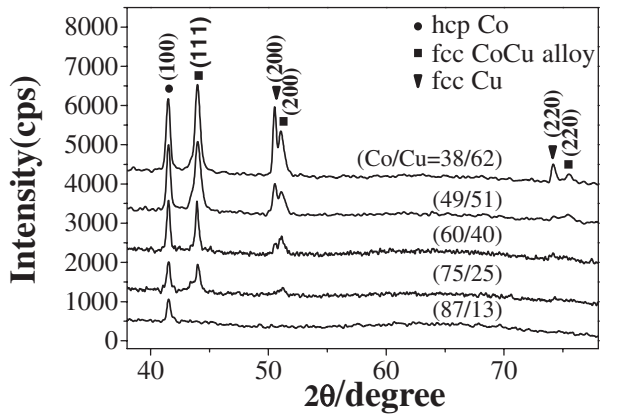

Figure 1. XRD of the nanowire arrays deposited at the same $\mathrm{pH}$ 3.3 and different depositing potentials.

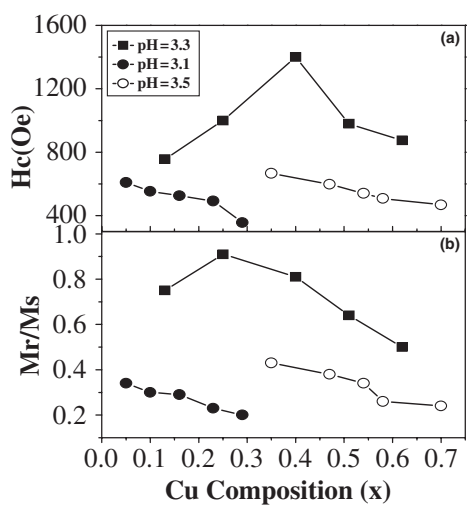

Figure 2. Coercivity (a) and squareness (b) of the as-deposited $\mathrm{Co}_{1-x} \mathrm{Cu}_{x}$ nanowire arrays deposited at different $\mathrm{pH}$ values and potentials.

means that the nanowires are preferentially oriented in this direction with a textured state. The reason for no sign of elementary $\mathrm{Cu}$ was found in this sample by XRD is due to the $\mathrm{Cu}$ stating in too small grains to be detectable. ${ }^{5}$ Increasing the depositing potential, the $\mathrm{Cu}$ content increases and more peaks which represent other phase gradually appear. The peaks located at 50.55 and $74.19^{\circ}$ belong to the pure $\mathrm{Cu}$ and the others stand for $\mathrm{CoCu}$ alloy based on their locations and the apparent wideness. ${ }^{7}$ Indexing the XRD, we have the lattice parameters for those phases: $a=2.509 \AA, c=4.096 \AA$ (hcp Co), $a=3.571 \AA$ (CoCu fcc alloy) and $a=3.600 \AA$ (fcc Cu). Thus, it can be confirmed that three phases, hcp $\mathrm{Co}$, fcc $\mathrm{CoCu}$ and elemental fcc $\mathrm{Cu}$ coexist in these nanowires. The portion of $\mathrm{CoCu}$ and $\mathrm{Cu}$ increases with the increase of the overall content of $\mathrm{Cu}$.

In the previous works, ${ }^{3,5}$ excepting for optimized $\mathrm{pH}$ value, many other modified depositing conditions were used to prepared $\mathrm{CoCu}$ nanowires in the different structures. But the acquired structures are always single phase: either hcp or fcc. No composite phase like we found in this work has been observed. This strongly suggests that the $\mathrm{pH}$ value condition is a very important condition to affect the structure of nanowires. Magnetizations of the array samples have been measured to reveal the composite effect to magnetic properties. Figure 2 shows the comparison of the magnetic properties between the single phase samples and the composite ones. These two kinds of sample cover the same $\mathrm{Co}-\mathrm{Cu}$ composition ranges and have the same diameter/length, but the composite samples show the apparently improved results: the peak values of the coercivity $H \mathrm{c}=1400 \mathrm{Oe}$ and the squareness $M_{\mathrm{r}} / M_{\mathrm{s}}=91 \%$, about three times higher than those of single phase samples. This should be attributed to the existence of the composite phase, hcp plus fcc structures with much more phase boundaries which enhance the domain pinning in the nanowires and increase the demagnetization field.

Composite $\mathrm{CoCu}$ nanowires have been successfully electrodeposited by using an optimized $\mathrm{pH}$ value. We found that, comparing to the depositing potential, the $\mathrm{pH}$ value has much stronger influence on dominating the composition and structures than the other depositing conditions. An apparent $\mathrm{pH}$ rule has been concluded. Based on it, the composite nanowires with the structure of hcp and fcc phase and a quite large composition range can be obtained. Their magnetic properties apparently precede to those in the single phase samples.

This work was supported by the CNNSF Grant No. 50471056, and the CNNSF Grant No. 50472034.

\section{References}

1 a) D. AlMawlawi, N. Coombs, M. Moskovits, J. Appl. Phys. 1991, 70, 4421. b) T. M. Whitney, P. C. Searson, J. S. Jiang, C. L. Chien, Science 1993, 261, 1316.

2 F. S. Li, T. Wang, L. Y. Ren, J. R. Sun, J. Phys.: Condens. Matter 2004, 16, 8053.

3 V. Scarani, B. Doudin, J. P. Ansermet, J. Magn. Magn. Mater. 1999, 205, 241.

4 J. U. Cho, J. H. Min, S. P. Ko, J. Y. Soh, Y. K. Kim, J.-H. Wu, S. H. Choi, J. Appl. Phys. 2006, 99, 08 C909.

5 a) H. J. Blythe, V. M. Fedosyuk, O. I. Kasyutich, W. Schwarzacher, J. Magn. Magn. Mater. 2000, 208, 2518. b) Y. W. Wang, L. D. Zhang, G. W. Meng, X. S. Peng, Y. X. Jin, J. Zhang, J. Phys. Chem. B 2002, 106, 2502. c) T. Ohgai, X. Hoffer, L. Gravier, J. P. Anserment, J. Appl. Electrochem. 2004, 34, 1007. d) T. Wang, F. S. Li, Y. Wang, L. J. Song, Phys. Status Solidi A 2006, 203, 2426.

6 a) Y. W. Wang, G. Z. Wang, S. X. Wang, T. Gao, H. Sang, L. D. Zhang, Appl. Phys. A 2002, 74, 577. b) G. B. Ji, S. L. Tang, W. Chen, B. X. Gu, Y. W. Du, Solid State Commun. 2004, 132, 289. c) H. N. Hu, H. Y. Chen, S. Y. Yu, L. J. Chen, J. L. Chen, G. H. Wu, J. Magn. Magn. Mater. 2006, 299, 170.

7 J. R. Childress, C. L. Chien, J. Appl. Phys. 1991, 70, 5885. 